\title{
EFFECT OF EXOGENOUS TRANSCRIPTION FACTORS INTEGRATION SITES ON SAFETY AND PLURIPOTENCY OF INDUCED PLURIPOTENT STEM CELLS
}

\begin{abstract}
Yin $\mathrm{S}^{1, *}$, Li W $\mathrm{W}^{2,3,{ }^{*}}$, Yang $\mathrm{G}^{2,3}$, Cheng $\mathrm{Y}^{2,3}$, Yi $\mathrm{Q}^{1}$, Fan $\mathrm{S}^{1,2,3}$, Ma $\mathrm{Q}^{2,3, \#}$, Zeng $\mathrm{F}^{1,2,3, \#}$
"Corresponding Author: Fanyi Zeng, M.D., Ph.D., Department of Histoembryology, Genetics and Development, Shanghai Jiao Tong University School of Medicine, 280 S. Chongqing Road, Shanghai, 200025, People's Republic of China. Tel: +86-21-6279-0545. Fax: +86-21-6247-5476. E-mail: fzeng@ vip.163.com; and Qingwen Ma, Ph.D., Shanghai Institute of Medical Genetics, Shanghai Children's Hospital, Shanghai Jiao Tong University, 24/1400 W. Beijing Road, Shanghai, 200040, People's Republic of China. Tel: +86-21-6279-0545. Fax: +86-21-6247-5476. E-mail: qwma1213@163.com
\end{abstract}

*Shang Yin and Wenxiu Li contributed equally to this study.

\begin{abstract}
Induced pluripotent stem cells (iPSCs), generated from somatic cells, not only possess similar characteristics with embryonic stem cells (ESCs), but also present more advantages than ESCs in medical applications. The classical induction method that utilizes the integration of exogenous genes into chromosomes may raise the potential risk of the safety of iPSCs. To investigate the potential correlation between the integration sites of exogenous transcription factors (TFs) and iPSCs' pluripotency and safety, the integration of exogenous genes in three iPSC lines, which met the golden standard of murine developmental assay (tetraploid complementation), were analyzed. Twenty-two integration sites of exogenous TFs were identified by nested inverse polymerase chain reaction (iPCR) and 39 flanking genes' functions were analyzed by gene ontology (GO). In the 22 integrated sites, 17 (77.3\%) were located in the intergenic regions and the remainder were located in introns far from the transcription start sites. Microarray analysis of the flanking genes in these cells showed that there was no distinct difference in expression levels between the iPSCs, ESCs and mouse embryonic

\footnotetext{
${ }^{1}$ Department of Histoembryology, Genetics and Development, Shanghai Jiao Tong University School of Medicine, Shanghai, People's Republic of China

${ }^{2}$ Shanghai Institute of Medical Genetics, Shanghai Children's Hospital, Shanghai Jiao Tong University, Shanghai, People's Republic of China

${ }^{3}$ National Health Commission Key Laboratory of Medical Embryogenesis and Developmental Molecular Biology \& Shanghai Key Laboratory of Embryo and Reproduction Engineering, Shanghai, People's Republic of China
}

fibroblast (MEF), suggesting that the integration of exogenous TFs has no significant influence on the expression of flanking genes. Gene ontology analysis showed that although most of the flanking genes were housekeeping genes, which were necessary for basic life activity, none of these 39 flanking genes have correlation with tumorigenesis or embryogenesis, suggesting that the integration sites hold low risk of tumorigenesis.

Keywords: Induced pluripotent stem cells (iPSCs); Integration sites; Pluripotency; Safety; Tetraploid complementation.

\section{INTRODUCTION}

In 2006, Takahashi and Yamanaka [1] generated induced pluripotent stem cells (iPSCs) through introducing Oct4, Sox 2, Klf4 and c-Myc into mouse fibroblasts. Later, numerous studies demonstrated that iPSCs and embryonic stem cells (ESCs) were similar in both the cell morphology and functions of self-renewal and differentiation into almost all cell types. Particularly, Zhao et al. [2] and Zhao et al. [3] reported the generation of viable and fertile mice through tetraploid complementation, an assay considered to be the most stringent test for pluripotency and developmental potency. The assay was performed in such a way that at the 2-cell embryo stage, the two cells were fused to create tetraploid (4N) embryos, which would normally cease to develop at a later stage, so that no viable embryos were generated. When the iPSCs were injected into these tetraploid embryos, the resulting embryos or animal must develop entirely from the injected iPSCs. Thus, the successful tetraploid complementation assay confirmed that iPSCs could attain true pluripotency that is extremely 
similar to embryonic stem cells (ESCs), generated from in vivo or nuclear transfer embryos [4,5]. Together with the fact that iPSCs were believed to have less of an ethics issue compared to ECSs, making them important and valuable resources for both medical applications and fundamental science research [6,7].

With promising potential for clinical application, human iPSCs provide hopeful resolutions for disease research, cell therapy and even organ transplantation. Human iPSCs can be derived from a patient's somatic cells, which can be differentiated into a disease model, such as Parkinson's and Huntington's models [8,9]. Compared with the use of traditional immortalized cell lines, patient-derived iPSCs can accurately reflect the drug response in patients, thus making them a valuable tool for screening new drug candidates $[10,11]$. In addition, iPSCs can also be the potential sources for curing some kind of genetic diseases. Hanna et al. [12] demonstrated that sickle cell anemia model mouse can be rescued by transplanting hematopoietic progenitors derived from corrected autologous iPSCs. And our laboratory also reported that the transplantation of iPSCs with the normal human $\beta$-globin gene into the $\beta^{+}$-thalassemia ( $\beta^{+}$-thal) IVS-II-654 (C>T) (HBB: c.316197C $>$ T) (http://globin.cse.psu.edu) blastocytes conditionally reversed the pathology of anemia [13]. In 2014, the first autologous iPSCs derived from retinal tissue were applied clinically $[14,15]$, representing the landmark of iPSCs that took the step from basic research to clinical application. Recently, a series of clinical trials were proposed and performed in Japan, the iPSCs were used to treat heart disease and Parkinson's disease [16-18]. Despite this, however, the iPSCs' safety is still an important issue before their application in stem cells and regenerative medicine. During the process of iPSCs induction by retrovirus, integration of viral DNA into host cells is an essential step. However, the random integration of the exogenous genes into genome of host cells may affect the pluripotency and safety of iPSCs [19], especially by inactivating some functional genes or activating pro-oncogene. To investigate the influence of exogenous transcription factors (TFs) to the pluripotency and safety of iPSCs, this study detected the integration sites of exogenous genes and the function of the flanking genes in three iPSC lines, which were shown to be fully pluripotent through tetraploid complementation assay, reported in our previous study [2].

\section{MATERIALS AND METHODS}

Nested Inverse Polymerase Chain Reaction. Nested inverse polymerase chain reaction (iPCR) was used to detect the integration sites of four exogenous transcriptional factors in three iPSC lines (Figure 1). Genome

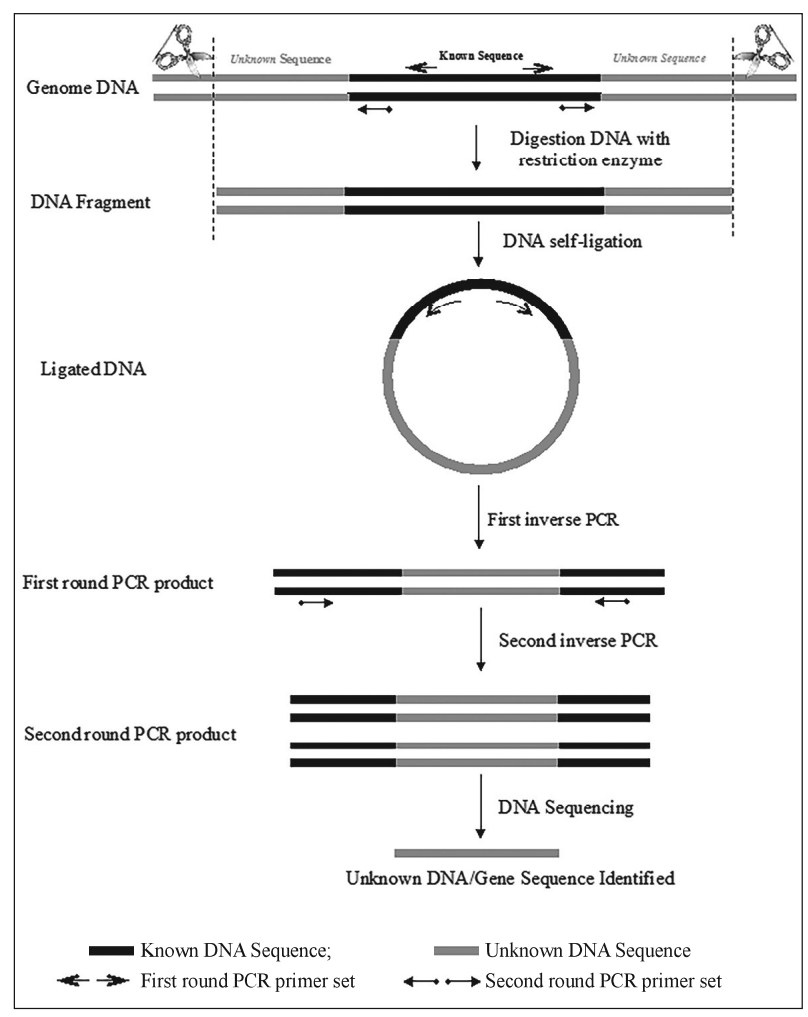

Figure 1. Schematic diagram of nested iPCR.

DNA fragmentation and circularization: iPSCs IP14D-1, IP14D-6, IP14D-101 [2] and mouse tail fibroblast cells (B6D2F1) were harvested. The genomic DNA was extracted [TIANamp genomic DNA kit; Tiangen Biotech, Beijing, People's Republic of China (PRC)], and then digested in $40 \mu \mathrm{L}$ of digestion reaction that contained 2 $\mu \mathrm{g}$ of genome DNA, $2 \mu \mathrm{L}$ BamHI, $2 \mu \mathrm{L} \mathrm{BglII}, 4 \mu \mathrm{L} 10 \times$ Fast Digest Buffer (Fermentas Life Science, St. Leon-Rot, Germany). After incubation in $37{ }^{\circ} \mathrm{C}$ for 4 hours, $5 \mu \mathrm{L}$ digests were electrophoresed in $0.9 \%$ agarose gel. The remaining digests were purified by QIAquick Gel Extract Kit (Qiagen $\mathrm{GmbH}$, Hilden, Germany) and then self-ligated within 1000U T4 DNA ligase (New England Biolabs Ltd., Hitchin, Hertfordshire, UK) in a $200 \mu \mathrm{L}$ reaction. After overnight incubation at $22{ }^{\circ} \mathrm{C}$, ligated DNA was purified and dissolved in $30 \mu \mathrm{L}$ water.

Nested iPCR Primer Designations. We designed the forward primers paired with the skeleton of the vector, and the inverse primers paired with exogenous TFs (Plasmid pMXs-Sox2: No.13367, pMXs-Oct4: No.13366, pMXsKlf4: No.13370, pMXs-c-Myc: No.13375; Addgene, Watertown, MA, USA) (Table 1).

First iPCR. The cyclized DNA from iPSCs IP14D-1, IP14D-6, IP14D-101 and mouse B6D2F1, were used as the template for PCR amplification in $25 \mu \mathrm{L}$ reaction system that contained $1 \mu \mathrm{L}$ of cyclized DNA, $0.75 \mu \mathrm{L}$ forward first iPCR primer and $0.75 \mu \mathrm{L}$ reverse first iPCR primer, 
Table 1. The primer sequences of nested inverse polymerase chain reaction

\begin{tabular}{|l|l|}
\hline Primer & Sequences $\left(\mathbf{5}^{\prime}>\mathbf{3}{ }^{\prime}\right)$ \\
\hline First iPCR-F & AAA ATA ATA ATA ACC GGG CAG GCC A \\
\hline First iPCR-Sox2-R & CCT TCT TCA TGA GCG TCT TGG TTT T \\
\hline First iPCR-Oct4-R & GTG TCC CTG TAG CCT CAT ACT CTT C \\
\hline First iPCR-Klf4-R & CTT TGC TAA CAC TGA TGA CCG AAG G \\
\hline First iPCR-c-Myc-R & TCT TCT CCA CAG ACA CCA CAT CAA T \\
\hline Second iPCR-F & CAG CAC AGT GGT CGA CGA TAAAAT A \\
\hline Second iPCR-Sox2-R & TTC AGC TCC GTC TCC ATC ATG TTA T \\
\hline Second iPCR-Oct4-R & TTT GCA TAT CTC CTG AAG GTT CTC A \\
\hline Second iPCR-Klf4-R & GGG TTA GCG AGT TGG AAA GGA TAAA \\
\hline Second iPCR-c-Myc-R & CCTCCAAGTAACTCGGTCATCATCT \\
\hline
\end{tabular}

iPCR: inverse polymerase chain reaction; $F$ : forward; R: reverse.

$2.5 \mu \mathrm{L}$ PCR buffer for KOD-Plus- (10×), $2.5 \mu \mathrm{L}$ dNTPs $(2$ $\mathrm{mM}$ ), $1 \mu \mathrm{L} \mathrm{MgSO}_{4}(2 \mathrm{mM}), 0.5 \mu \mathrm{L}$ KOD-Plus- (Toyobo Co. Ltd., Osaka, Japan). The reaction condition was $94^{\circ} \mathrm{C}$ for 2 min., 25 cycles at $94{ }^{\circ} \mathrm{C}$ for 15 seconds, $60^{\circ} \mathrm{C}$ for 30 seconds, $68^{\circ} \mathrm{C}$ for $3.5 \mathrm{~min}$.

Second iPCR. The secondary iPCR system used 1 $\mu \mathrm{L}$ product of the first iPCR as template and the primers were $0.75 \mu \mathrm{L}$ forward second iPCR primer and $0.75 \mu \mathrm{L}$ reverse second iPCR primer, followed the same program as the first iPCR. The reaction condition was $94{ }^{\circ} \mathrm{C}$ for 2 min., 25 cycles at $94{ }^{\circ} \mathrm{C}$ for 15 seconds, $60{ }^{\circ} \mathrm{C}$ for 30 seconds, $68^{\circ} \mathrm{C}$ for $3.5 \mathrm{~min}$.

The second PCR product was electrophoresed on $1.0 \%$ agarose, the specific fragment was recycled for sequencing. To find the integration sites of the exogenous TFs, the target and vectors sequence were aligned using BLAST (https://blast.ncbi.nlm.nih.gov/Blast.cgi).

Microarray Data Analysis of Flanking Genes. After confirmation of the integration sites, expressing pattern of the flanking genes of the integration sites in IP14D-1, IP14D-6, IP14D-101, mouse embryonic fibroblast (MEF), and ESCs were compared using the global expression analysis (part microarray data were obtained from the Gene Expression Omnibus repository, accession number GSE16925; https://ncbi.nlm.nih.gov/geo/).

Gene Oncology and Cluster Analysis of Flanking Genes. To verify whether the flanking genes were related to development, cell differentiation or cancer, functions of the flanking genes were analyzed using the online database MGI (http://www.informatics.jax.org/). Moreover, cluster analysis was used to investigate the functions of the flanking genes and to identify whether any important signaling pathways were involved. In addition, we analyzed the $500 \mathrm{~kb}$ of downstream and upstream flanking genes from the integration sites through mouse genomic information. To verify whether these genes were associated with tumorigenesis, flanking genes with known oncogenes were compared according to the database described by Akagi et al. [20].

\section{RESULTS}

Identification of Transgene Integration Sites. Electrophoresis results of digested genomic DNA showed large diffused bands, indicating that the genomic DNA were digested completely [Figure 2(A)], while nested iPCR products displayed multiple bands, indicating multiple integration sites of exogenous TFs in iPSCs [Figure 2(B)]. Through alignment of the specific sequence, we identified 22 integration sites for the four TFs in three different iPSC lines, in which 17 (77.3\%) were located in intergenic regions, and five $(22.7 \%)$ were located in introns far from the transcription start sites.

Expression Profile Analysis of Flanking Genes of Integration Sites. For the 22 sites above, 39 flanking genes were involved (Table 2). Of the 39 flanking genes, five genes including LOC101055956, LOC105244150, Olfr456, Olfr455 and Nanos3, were not expressed in iPSCs, MEF or ESCs. The expression patterns of the

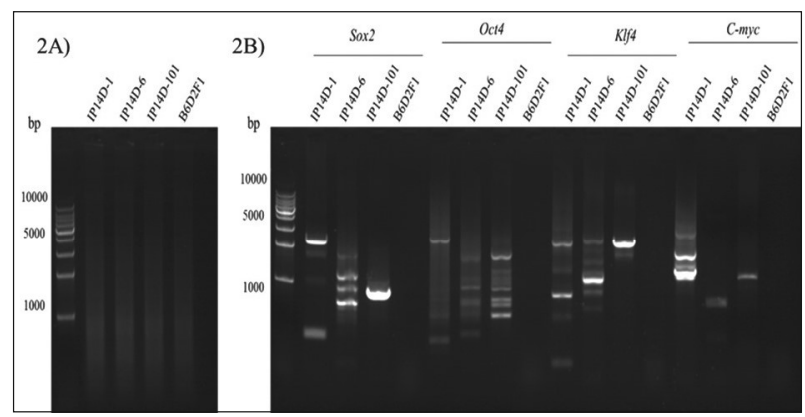

Figure 2. Nested iPCR. (A) Restriction digestion of genomic DNA. M: $1 \mathrm{~kb}$ marker. (B) The result of nested iPCR. M: $1 \mathrm{~kb}$ marker; Oct4, Sox2, Klf4, c-Myc: exogenous TFs. 
Table 2. The identified integration sites and their flanking genes.

\begin{tabular}{|c|c|c|c|c|c|c|c|c|c|}
\hline \multirow{2}{*}{$\begin{array}{c}\text { Reprogramming } \\
\text { Factors }\end{array}$} & \multirow[b]{2}{*}{ iPSCs } & \multirow{2}{*}{$\begin{array}{l}\text { Chromosome No. } \\
\text { of Integration Site }\end{array}$} & \multirow{2}{*}{$\begin{array}{l}\text { GenBank } \\
\text { Acc. No. }\end{array}$} & \multirow{2}{*}{$\underset{\text { Site }}{\text { Integration }}$} & \multirow[b]{2}{*}{ Gene } & \multicolumn{4}{|c|}{ Flanking Genes and Their Distance } \\
\hline & & & & & & 5 & $\begin{array}{c}\begin{array}{c}\text { Distance } \\
(\mathbf{k b})\end{array} \\
\end{array}$ & 3' & $\begin{array}{c}\text { Distance } \\
(\mathbf{k b})\end{array}$ \\
\hline \multirow[t]{7}{*}{ Sox 2} & IP14D-1 & 10 & NC_000076.6 & intergenic & & Phldal & 8.3 & Krrl & 450.0 \\
\hline & & 10 & NC_000076.6 & intergenic & & Aldh8al & 301.0 & $S g k 1$ & 185.0 \\
\hline & IP14D-6 & 1 & NC_000076.6 & intergenic & & Cops $7 b$ & 28.2 & $N p p c$ & 35.7 \\
\hline & IP14D-101 & 11 & NC_000077.6 & introns & Vat1 & & & & \\
\hline & & 8 & NC_000074.6 & intergenic & & Nanos 3 & 20.9 & Zswim4 & 14.3 \\
\hline & IP14D-1 & 15 & NC_000081.6 & intergenic & & Cdh6 & 2390.0 & LOC 101055956 & 461.1 \\
\hline & & 14 & NC_000080.6 & intergenic & & Rarb & 287.3 & Thrb & 554.7 \\
\hline \multirow[t]{7}{*}{ Oct4 } & IP14D-6 & 16 & NC_000082.6 & intergenic & & Atp13a3 & 111.0 & Tmem44 & 14.1 \\
\hline & & 7 & NC_000073.6 & introns & Samd4 & & & & \\
\hline & IP14D-101 & 5 & NC_000071.6 & intergenic & & Alox5ap & 102.8 & Medag & 15.7 \\
\hline & & 2 & NC_000068.6 & introns & Slcl3a3 & & & & \\
\hline & & 7 & NC_000073.6 & intergenic & & Rassf10 & 196.2 & Arntl & 128.1 \\
\hline & IP14D-1 & 8 & NC_000074.6 & intergenic & & Kbtbd11 & 2.7 & Myom 2 & 25.4 \\
\hline & & 5 & NC_000071.6 & intergenic & & Fryl & 57.7 & LOC 105244150 & 5.8 \\
\hline \multirow[t]{5}{*}{ Klf4 } & & 6 & NC_000072.6 & introns & Jagn1 & & & & \\
\hline & IP14D-6 & 11 & NC_000077.6 & intergenic & & Hspa4 & 6.3 & Zcche10 & 18.1 \\
\hline & IP14D-101 & 4 & NC_000070.6 & intergenic & & Lsm10 & 13.8 & Stk 40 & 6.2 \\
\hline & & 6 & NC_000072.6 & intergenic & & Ankrd7 & 1579.0 & Kcnd2 & 766.4 \\
\hline & IP14D-1 & 3 & NC_000069.6 & intergenic & & $A b c d 3$ & 126.2 & Arhgap 29 & 33.7 \\
\hline \multirow[t]{3}{*}{$c-M y c$} & & 6 & NC_000072.6 & intergenic & & Olfr 456 & 1.4 & Olfr 455 & 49.3 \\
\hline & IP14D-6 & 8 & NC_000074.6 & introns & Dctn6 & & & & \\
\hline & IP14D-101 & 6 & NC_000072.6 & intergenic & & Kcna4 & 459.7 & Mettl15 & 1289.0 \\
\hline
\end{tabular}

iPSCs: induced pluripotent stem cells; No.: number; Acc. No.: access number.

remaining 34 genes in three iPSC lines, MEF and ESCs were compared, and no distinct expression difference was observed in these cells (Figure 3), indicating that the integration of exogenous genes did not activate the expression of flanking genes.

Functional Analysis of Flanking Genes of Integration Sites. For the 39 flanking genes, none of them was found to have the function as early embryonic development or cancer-related genes (Table 3 ). Of the five flanking genes mentioned above, Olfr 456 and Olfr 455 were olfactory receptors that were specifically expressed in olfactory cells [21,22], while Nanos 3 was involved in spermatogenesis and specific expressed in germ cells [23]. LOC101055956 and LOC105244150 are predicted genes, and the other 34 genes are necessary for normal life activities. On the other hand, the cluster analysis results showed that these genes have different functions and were involved in different metabolic activities. Moreover, no common function was found in early embryonic development or differentiation between these genes except that some of them, including LSM10, were relative to cartilage development (Figure 4). Addi- tionally, we further studied the function of genes located $500 \mathrm{~kb}$ upstream and downstream from integration sites and none of the genes that related to tumorigenesis was found in that range. Taken together, we concluded that the integration of exogenous genes would not influence the safety of iPSCs.

\section{DISCUSSION}

Once the first successful induction of pluripotent stem cells from adult cells, Hanna et al. [12] demonstrated that iPSCs could be used to treat sickle cell anemia in the mouse model. Later, Raya et al. [6] obtained disease-corrected, patient-specific iPSCs that can be used for cell therapy without immune rejection. Using chimera models, Yang et al. [13] demonstrated that gene-modified iPSCs derived from the $\beta^{+}$-thal IVS-II-654 mouse significantly improved the disorders in $\beta^{+}$-thal IVS-II-654 mice, especially when the chimerism of iPSCs with normal human $\beta$-globin gene was more than $30.0 \%$. 


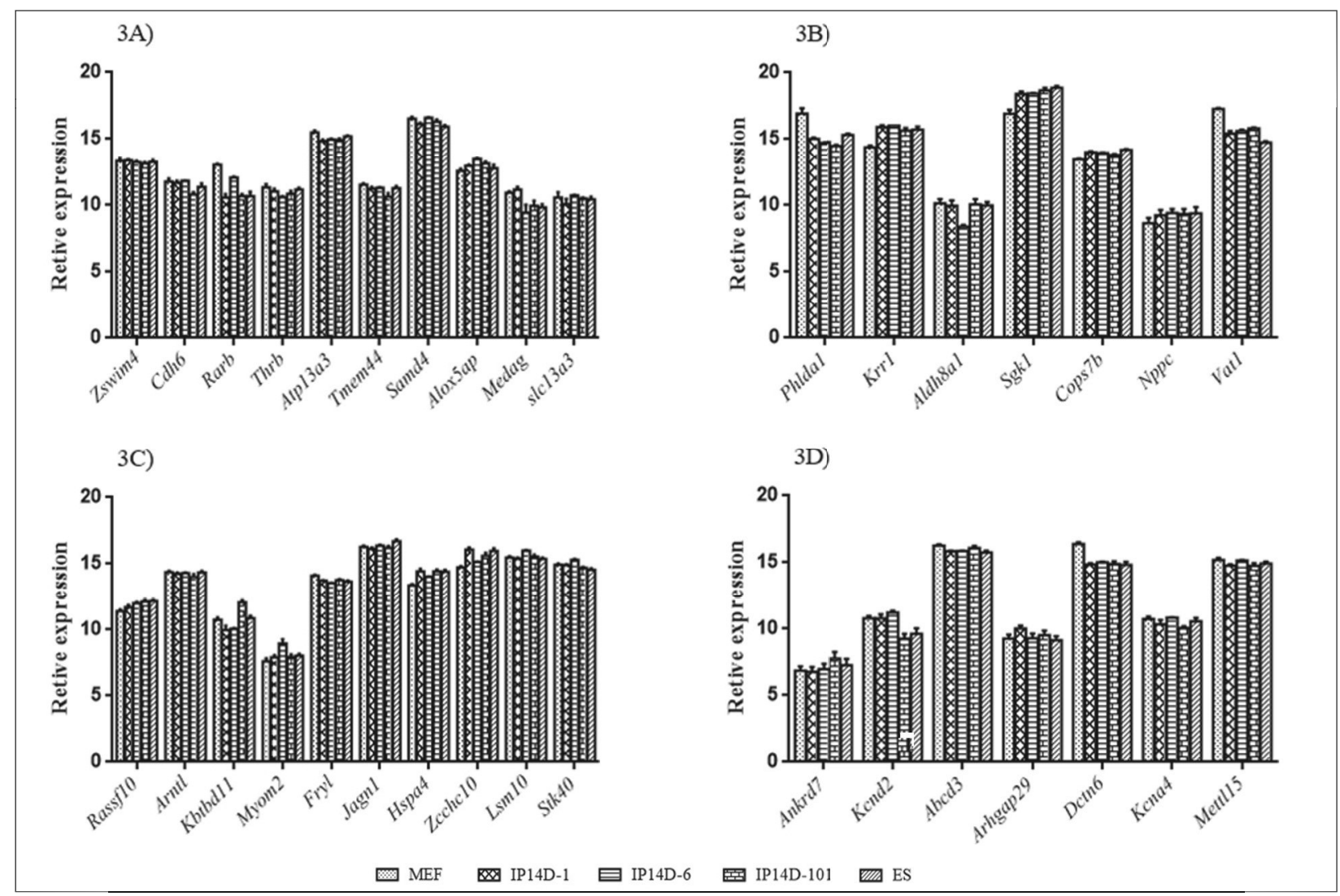

Figure 3. Expression profiles of flanking genes from microarray analysis. (A) Expression profiles of Oct4 flanking genes. (B) Expression profiles of Sox 2 flanking genes. (C) Expression profiles of Klf4 flanking genes. (D) Expression profiles of $c-M y c$ flanking genes.

The traditional method of pluripotent cell induction is transferring the exogenous TFs into MEF via retrovirus. However, retrovirus can randomly integrate the exogenous genes into host cells with multiple copies, which may inactivate the tumor suppressor genes or activate the protooncogene or make any frameshift mutation [24]. Thus, retrovirus could probably influence the pluripotency and safety of iPSCs. Despite that the pluripotency of iPSCs has been confirmed through the tetraploid complementa- tion assay [2], the exogenous TFs' integration sites can still influence the development and health of the iPSCsderived mice.

To investigate possible issues with these integration sites, nested iPCR [25] was performed in three iPSC lines previously identified to be pluripotent through the tetraploid complementation assay [2]. A total of 22 integration sites were identified, $77.3 \%$ (17) were located in the intergenic region, while $22.7 \%$ (five) were within introns

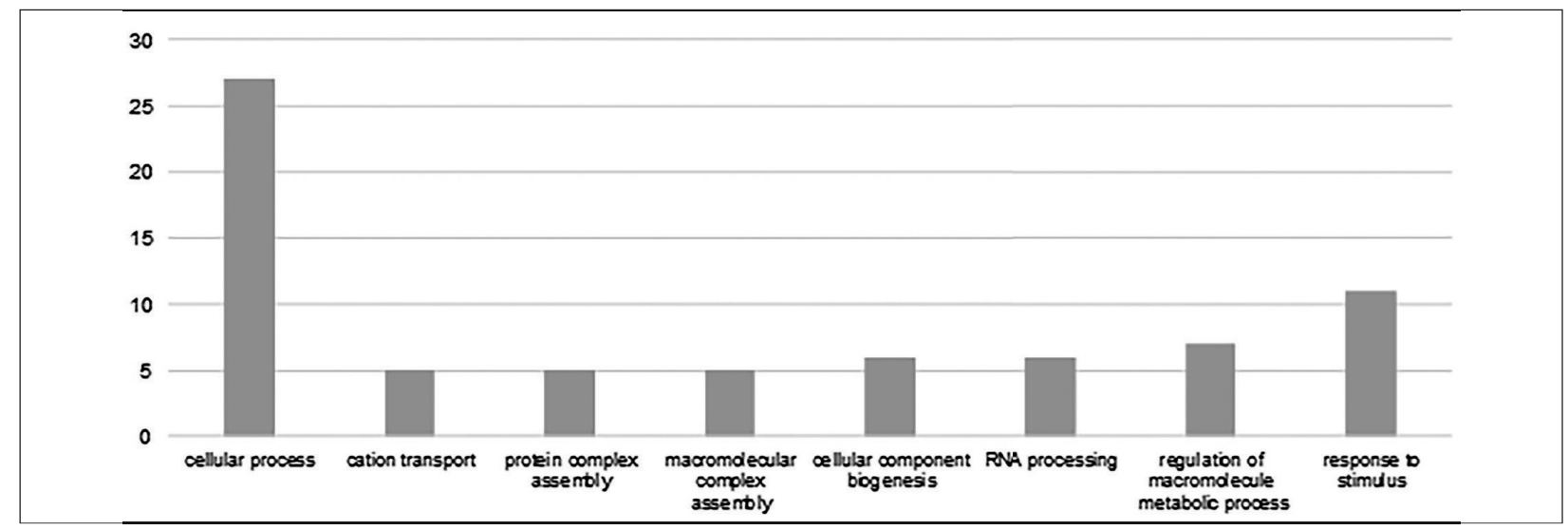

Figure 4. The GO classification of flanking genes. 
Table 3. The molecular functions of flanking genes.

\begin{tabular}{|c|c|c|}
\hline Genes & Function & Mainly Process Involved \\
\hline Phldal & protein binding & cell apoptosis; programmed cell death \\
\hline Krrl & RNA binding; POLY-A binding & biosynthesis of ribosomes; rRNA process \\
\hline Vatl & $\mathrm{Zn}^{2+}$ binding; oxioreductase activity & negative regulation of mitochondrial fusion; redox \\
\hline Lsm10 & RNA binding; histone precursor mRNA binding & positive regulation of mitosis from $\mathrm{G} 1$ to $\mathrm{S}$ phase \\
\hline Stk40 & kinase activation; ATP binding & embryonic ectoderm differentiation; glucose metabolism \\
\hline Nanos3 & RNA binding; $\mathrm{Zn}^{2+}$ binding & oogenesis; spermatogenesis \\
\hline Zswim4 & metal ion binding; $\mathrm{Zn}^{2+}$ binding & biochemical process \\
\hline Samd4 & POLY-A binding & negative regulation process of synapse; translation \\
\hline Alox5ap & protein binding; enzyme binding & metabolism process of leukotrienes \\
\hline Medag & catalysis; binding & adipocyte differentiation \\
\hline Rassf10 & catalysis; binding & biochemical processes; signal transduction \\
\hline Arntl & DNA binding; RNA binding; protein binding & regulation of gene expression related to circadian clock \\
\hline Hspa4 & ATP binding; protein complex binding & introduction of mitrochondrial outer membrance proteins \\
\hline Zcchc10 & metal ion binding & biochemical processes \\
\hline Ankrd7 & catalysis; binding & support cell maturation \\
\hline Kcnd2 & ion channel activation & $\mathrm{K}^{+}$transmembrane transport \\
\hline Dctn6 & kinetic protein binding & motochondrial cavity \\
\hline Olfr 456; Olfr 455 & protein binding & olfactory receptors; signal transduction \\
\hline Atp13a3 & ATP binding; ATP enzyme activation & $\mathrm{Na}^{+}$transmembrane transport; cation transport \\
\hline Tmem44 & transmembrane protein binding & biochemical processes \\
\hline Kbtbdl1 & N/A & transcriptional regulation \\
\hline Myom2 & components of cytoskeleton structural & muscle contraction \\
\hline Jagnl & molecular function (basic cell activity) & $\begin{array}{l}\text { neutrophil-mediated immune response; } \\
\text { fungal-induced immune response }\end{array}$ \\
\hline Fryl & protein binding & biochemical processes \\
\hline Cops $7 b$ & transmembrane protein functional molecule & deubiquitination \\
\hline$N p p c$ & peptide hormone receptor binding; hormone activity & vasodilation; endochondral growth \\
\hline Aldh8a1 & aldehyde dehydrogenase activity & retinoic acid metabolism \\
\hline Sgkl & ATP binding; protein binding; kinase activity & $\begin{array}{l}\text { positive regulation of } \mathrm{Na}^{+} \text {transportation; } \\
\text { negative regulation of apoptosis }\end{array}$ \\
\hline$A b c d 3$ & ATP binding; protein binding & transmembrane transportation; long chain fatty acid metabolism \\
\hline Arhgap29 & activity of GDP enzyme; protein binding & intercellular signal transduction \\
\hline Cdh6 & $\mathrm{Ca}^{2+}$ binding; metal ion binding & cell adhesion \\
\hline Slcl3a3 & cotransport activity; transmembrane transport activity & succinic acid transportation; $\mathrm{Na}^{+}$transportation \\
\hline Rarb & binding; retinoic acid receptor & $\begin{array}{l}\text { positive regulation of cell proliferation; } \\
\text { digestive system development; neurogenesis }\end{array}$ \\
\hline$T h r b$ & thyroxine; activity of receptor thyroxine & intracellular receptor of signaling pathway; organ morphonenesis \\
\hline Mettll5 & activity of methyltransferase & methylation; ribosomal methylation \\
\hline Kcna4 & $\mathrm{K}^{+}$binding; ion channel activation & ion transport; $\mathrm{K}^{+}$transmembrane transport \\
\hline
\end{tabular}

POLY-A: polyadenylic acid; $\mathrm{Zn}^{2+}$ : zinc ions; ATP: adenosine triphosphate; N/A: not available; GDP enzyme: guanosine 5'-diphosphates enzyme;

$\mathrm{Ca}^{2+}$ : calcium ions; $\mathrm{K}^{+}$: potassium ions.

LOC101055956 and LOC105244150 are predicted genes, the function and mainly process involvement is as yet unknown.

far from the transcription start sites. Expressional profiles of 39 flanking genes were analyzed and functions of these flanking genes were reviewed in the iPSCs, ESCs and
MEF. Our results showed that these flanking genes have no distinct difference in the expression levels in the three iPSC lines, MEF and ESCs. Moreover, none of the 39 flanking 
genes correlated to early embryonic development or differentiation, and most of them belonged to housekeeping genes, which are necessary for the basic life events of cells.

It is generally recognized that retroviral integration sites were randomly distributed in multiple chromosomes [26]. In this study, these transgene integration sites were widely distributed throughout the mouse chromosomes and no common integration sites were detected in these iPSCs, which was similar to the previous studies in the iPSCs derived from adult mouse cells [27,28]. However, reports showed retroviral vectors such as murine leukemia virus (MLV) and human immunodeficiency virus (HIV) have preferences for integration sites in the human genome [29]. The HIV was prone to integrate into active genes, while MLV favored integrating near transcription-start regions [29]. In our study, these transgene integration sites mainly resided in the intergenic regions, and it appeared that there is no effect on the function of the flanking genes. Moreover, many of the flanking genes were found to be housekeeping genes, suggesting a friendly environment for the expression of exogenous TFs for iPSCs induction. Thus, we speculated that these clones contained retroviral integration sites in active genes and transcription-start regions may have no capability to finish the correct reprogramming and generate iPSCs, while the clones that have no integration sites in these related locations could be induced into iPSCs. In addition, specific differences may also give rise to integration bias of retroviral vectors in different species. Locus control region (LCR) and gene-proximal elements, which could affect the transcription of genes by recruiting coactivator, transcription complexes or RNA polymerase, play an important role in gene expression [30,31]. In the process of iPSCs induction, these LCR and gene-proximal elements could be disrupted by the retroviral integration. However, according to our previous reports, these iPSCs in this research have the similar transcription pattern with ESCs, implying the integration of retroviral vector has no distinct effect on the transcription of genes [2]. Theoretically, the integrality of LCR and gene-proximal elements is essential for iPSCs to pass the tetraploid complementation assay and generate live pups. In this study, for the five genes that contain retroviral integration in their introns, the expression level showed no obvious difference in iPSCs, MEF and ESCs, suggesting the integrality of LCR and gene-proximal elements. In future, we could induce the homozygous mouse that contains retroviral integration in indicated intron to study the effect of intron integration. Additionally, for the integration sites detection, PCR was the common method. However, this method was timeconsuming and it was hard to get an integrated map of the insertion sites. Along with the advancement of the science and technology, new technical approach such as
CRISPR/Cas9 was developed to study structural variants in mammalian genomes [32]. In future, we could also use new technologies to study the insertion sites, and to further study the stability of gene expression in iPSCs.

The mechanisms of tumorigenesis by iPSCs are probably attributed to two aspects. One might be related to the exogenous TFs Klf4 and C-Myc, as these two proto-oncogenes can facilitate cell proliferation and transformation through regulating the expression and activity of downstream proteins, eventually leading to malignant proliferation [33]. The other is the integration sites of exogenous TFs. Sadelain et al. [34] summarized the features of safe integration sites on the human genome and considered that two genes hardly influence each other when their distance is more than $300 \mathrm{~kb}$. Thus, we further studied the $500 \mathrm{~kb}$ of downstream and upstream genes from integration sites, and no tumor-related gene was found in this range. Our results suggested that integration sites probably have no effect on the safety of iPSCs. This was consistent with the research that the tetraploid complementation mice derived from iPSCs in this study was similar to mice derived from ESCs in both intelligence and development, which proved that these iPSCs possess totipotency [35]. Overall, we conclude that the integration of exogenous genes did not affect the expression of the flanking genes, and the stable expression of the flanking genes offered a safe environment for iPSCs.

\section{ACKNOWLEDGMENTS}

The authors would like to thank Professor Qi Zhou at the Institute of Zoology, Chinese Academy of Sciences, Beijing, PRC.

Declaration of Interest. The authors report no conflicts of interest. The authors alone are responsible for the content and writing of this article.

Funding. This study was supported by grants from the China National Basic Research Program [2014CB964701 and 2014CB964703], National Natural Science Foundation of China [31371486], the Science and Technology Commission of the Shanghai Municipality (STCSM Project) [14JC1405700 and 16ZR1428600].

\section{REFERENCES}

1. Takahashi K, Yamanaka S. Induction of pluripotent stem cells from mouse embryonic and adult fibroblast cultures by defined factors. Cell. 2006; 126(4): 663-676.

2. Zhao XY, Li W, Lv Z, Liu L, Tong M, Hai T, et al. iPS Cells produce viable mice through tetraploid complementation. Nature. 2009; 461(7260): 86-90. 
3. Zhao XY, Lv Z, Liu W, Zeng F, Zhou Q. Production of mice using iPS cells and tetraploid complementation. Nat Protoc. 2010; 5(5): 963-971.

4. Thomson JA, Itskovitz-Eldor J, Shapiro SS, Waknitz MA, Swiergiel JJ, Marshall VS, et al. Embryonic stem cell lines derived from human blastocysts. Science. 1998; 282(5391): 1145-1147.

5. Wilmut I, Schnieke AE, McWhir J, Kind AJ, Campbell KH. Viable offspring derived from fetal and adult mammalian cells. Nature. 1997; 385(6619): 810-813.

6. Raya A, Rodriguez-Piza I, Guenechea G, Vassena R, Navarro S, Barrero MJ, et al. Disease-corrected haematopoietic progenitors from Fanconi anaemia induced pluripotent stem cells. Nature. 2009; 460(7251): 53-59.

7. Reboun M, Rybova J, Dobrovolny R, Vcelak J, Veselkova T, Storkanova G, et al. X-Chromosome inactivation analysis in different cell types and induced pluripotent stem cells elucidates the disease mechanism in a rare case of mucopolysaccharidosis type II in a female. Folia Biol (Praha). 2016; 62(2): 82-89.

8. Kaye JA, Finkbeiner S. Modeling Huntington's disease with induced pluripotent stem cells. Mol Cell Neurosci. 2013; 56: 50-64.

9. Byers B, Lee HL, Reijo Pera R. Modeling Parkinson's disease using induced pluripotent stem cells. Curr Neurol Neurosci Rep. 2012; 12(3): 237-42.

10. Egawa N, Kitaoka S, Tsukita K, Naitoh M, Takahashi $\mathrm{K}$, Yamamoto T, et al. Drug screening for ALS using patient-specific induced pluripotent stem cells. Sci Transl Med. 2012; 4(145): 145ra104.

11. Sala L, Yu Z, Ward-van Oostwaard D, van Veldhoven JP, Moretti A, Laugwitz KL, et al. A new hERG allosteric modulator rescues genetic and drug-induced long-QT syndrome phenotypes in cardiomyocytes from isogenic pairs of patient induced pluripotent stem cells. EMBO Mol Med. 2016; 8(9): 1065-1081.

12. Hanna J, Wernig M, Markoulaki S, Sun CW, Meissner A, Cassady JP, et al. Treatment of sickle cell anemia mouse model with iPS cells generated from autologous skin. Science. 2007; 318(5858): 1920-1923.

13. Yang G, Shi W, Hu X, Zhang J, Gong Z, Guo X, et al. Therapeutic effects of induced pluripotent stem cells in chimeric mice with $\beta$-thalassemia. Haematologica. 2014; 99(8): 1304-1311.

14. Mandai M, Watanabe A, Kurimoto Y, Hirami Y, Morinaga C, Daimon T, et al. Autologous induced stem-cell-derived retinal cells for macular degeneration. N Engl J Med. 2017; 376(11): 1038-1046.
15. Sugita S, Iwasaki Y, Makabe K, Kamao H, Mandai M, Shiina T, et al. Successful transplantation of retinal pigment epithelial cells from MHC momozygote iPSCs in MHC-matched models. Stem Cell Rep. 2016; 7(4): 635-648.

16. Cyranoski D. 'Reprogrammed' stem cells approved to mend human hearts for the first time. Nature. 2018; 557(7707): 619-620.

17. Kikuchi T, Morizane A, Doi D, Magotani H, Onoe $\mathrm{H}$, Hayashi $\mathrm{T}$, et al. Human iPS cell-derived dopaminergic neurons function in a primate Parkinson's disease model. Nature. 2017, 548(7669):592-596.

18. Cyranoski D. 'Reprogrammed' stem cells implanted into patient with Parkinson's disease. Nature News, November 2018 (https://www.nature.com/articles/ d41586-018-07407-9).

19. Takahashi K, Tanabe K, Ohnuki M, Narita M, Ichisaka $\mathrm{T}$, Tomoda $\mathrm{K}$, et al. Induction of pluripotent stem cells from adult human fibroblasts by defined factors. Cell. 2007; 131(5): 861-872.

20. Akagi K, Suzuki T, Stephens RM, Jenkins NA, Copeland NG. RTCD: Retroviral tagged cancer gene database. Nucleic Acids Res. 2004; 32(Suppl 1): D523D527.

21. Zhang $X$, Firestein S. The olfactory receptor gene superfamily of the mouse. Nat Neurosci. 2002; 5(2): 124-133.

22. Young JM, Shykind BM, Lane RP, Tonnes-Priddy L, Ross JA, Walker M, et al. Odorant receptor expressed sequence tags demonstrate olfactory expression of over 400 genes, extensive alternate splicing and unequal expression levels. Genome Biol. 2003; 4(11): R71.

23. DiMagno MJ, Williams JA, Hao Y, Ernst SA, Owyang C. Endothelial nitric oxide synthase is protective in the initiation of caerulein-induced acute pancreatitis in mice. Am J Physiol Gastrointest Liver Physiol. 2004; 287(1): G80-G87.

24. Vaughan AE, Halbert CL, Wootton SK, Miller AD. Lung cancer in mice induced by the Jaagsiekte sheep retrovirus envelope protein is not maintained by rare cancer stem cells, but tumorigenicity does correlate with Wnt pathway activation. Mol Cancer Res. 2012; 10(1): 86-95.

25. Ochman H, Gerber AS, Hartl DL. Genetic applications of an inverse polymerase chain reaction. Genetics. 1988; 120(3): 621-623.

26. Telesnitsky A, Goff SP. Reverse transcriptase and the generation of retroviral DNA. In: Coffin JM, Hughes $\mathrm{SH}$, Varmus HE, Editors. Retroviruses. Cold Spring 
Harbor (NY, USA): Cold Spring Harbor Laboratory Press. 1997: 121-160.

27. Varas F, Stadtfeld M, de Andres-Aguayo L, Maherali $\mathrm{N}$, di Tullio A, Pantano L, et al. Fibroblast-derived induced pluripotent stem cells show no common retroviral vector insertions. Stem Cells. 2009; 27(2): 300-386.

28. Aoi T, Yae K, Nakagawa M, Ichisaka T, Okita K, Takahashi K, et al. Generation of pluripotent stem cells from adult mouse liver and stomach cells. Science. 2008; 321(5889): 699-702.

29. Mitchell RS, Beitzel BF, Schroder AR, Shinn P, Chen H, Berry CC, et al. Retroviral DNA integration: ASLV, HIV, and MLV show distinct target site preferences. PLoS Biol, 2004; 2(8): E234.

30. Li Q, Peterson KR, Fang X, Stamatoyannopoulos G. Locus control regions. Blood. 2002; 100(9): 30773086.

31. McNamara-Schroeder KJ, Hennessey RF, Harding GA, Jensen RC, Stumph WE. The Drosophila U1 and
U6 gene proximal sequence elements act as important determinants of the RNA polymerase specificity of small nuclear RNA gene promoters in vitro and in vivo. J Biol Chem. 2001; 276(34): 31786-31792.

32. Slesarev A, Viswanathan L, Tang Y, Borgschulte T, Achtien K, Razafsky D, et al. CRISPR/CAS9 targeted CAPTURE of mammalian genomic regions for characterization by NGS. Sci Rep. 2019; 9(1): 3587.

33. Adhikary S, Eilers M. Transcriptional regulation and transformation by Myc proteins. Nat Rev Mol Cell Biol. 2005; 6(8): 635-645.

34. Sadelain M, Papapetrou EP, Bushman FD. Safe harbours for the integration of new DNA in the human genome. Nat Rev Cancer. 2012; 12(1): 51-58.

35. Tong M, Lv Z, Liu L, Zhu H, Zheng QY, Zhao XY, et al. Mice generated from tetraploid complementation competent iPS cells show similar developmental features as those from ES cells but are prone to tumorigenesis. Cell Res. 2011; 21(11): 1634-1637. 